\title{
Valvotomy in calcific mitral stenosis
}

\author{
G. H. Smith and J. R. Belcher \\ From the London Chest Hospital, London E.2
}

The results of transventricular mitral valvotomy in 50 cases of heavily calcified mitral stenosis are presented.

The mortality and quality of results in patients undergoing a first valvotomy were more satisfactory than in patients undergoing a second operation. Associated mitral incompetence has an adverse effect on the results, particularly after a second operation.

As a result, it is suggested that closed valvotomy, in these circumstances, is only acceptable for patients who are undergoing a first operation and who have minimal or no regurgitation. Valve replacement is advised for all other cases.

Palpation of the diseased mitral valve at operation gives valuable information as to the most suitable type of operation for that valve. Calcium deposits are often felt in the stenosed mitral valve, and a decision has to be made between splitting the valve under closed conditions and open operation with possible replacement.

We have studied the results of transventricular mitral valvotomy in patients with mitral stenosis who were judged to have heavy calcification of the valve. These results form the basis of this paper.

\section{Subjects and methods}

From January 1958 to December 1966, 47 I patients with mitral stenosis had transventricular valvotomy performed by one of us (J.R.B.). Of these, 53 had heavily calcified mitral valves; the diagnosis of calcification had been made, in each case, by palpation of the valve cusps at operation. 'Heavy' calcification was recorded when calcification was found throughout both cusps.

In July and August 1968, the notes of these 53 patients were studied and those surviving were written to and asked to attend for assessment.

Each patient who responded was seen by one of us (G.H.S.) who previously had not been assoeiated with any of the group. The patient was questioned closely about the severity of symptoms before and after operation. An assessment was made of present exercise tolerance. Clinical examination was performed, special attention being directed to signs of mitral disease, especially regurgitation. Chest $x$-rays and electrocardiograms were performed on all patients. The clinical and electrocardiographic

Received 2 September 1969. assessment was then graded as 'good', 'fair', or 'poor' according to the following criteria.

(I) Good: an increase of one grade or more in exercise tolerance (as judged by New York Heart Association Classification), and with no sign or minimal signs of mitral valve disease as well as no sign of hypertrophy of either ventricle in the electrocardiogram.

(2) Fair: an increase in exercise tolerance of one grade or more, and with associated signs of mitral valve disease of significant degree and signs of ventricular hypertrophy in the electrocardiogram.

(3) Poor: unaltered or diminished exercise tolerance with signs of significant mitral valve disease.

The chest $x$-ray of each patient was studied and graded as 'good', 'fair', or 'bad' according to the following criteria.

(I) Good: a diminution or no change in the cardiothoracic ratio; there was diminution or no change in the size of the various cardiac chambers and there was no sign of pulmonary venous congestion.

(2) Fair: chest $x$-rays showing one of the following features: increase in cardiothoracic ratio, increase in size of a cardiac chamber, or signs of pulmonary venous congestion.

(3) Bad: chest $x$-rays showing two or more of the following features: increase in cardiothoracic ratio, increase in size of a cardiac chamber, or signs of pulmonary venous congestion.

The records of the patients who had died and of those who had failed to attend for follow-up were studied. Some patients had been inadequately followed since their operation and these had to be excluded. Those who had been adequately followed, so that data could be obtained in order to grade them according to the above clinical and radiological criteria, have been included.

The operative notes of all patients were studied to find the state of the mitral valve before and 
after the transventricular dilatation. Regurgitation, stenosis, and the degree of split obtained were recorded. These features were assessed by the exploring finger. The disadvantages of this are that such observations are highly subjective and occur in unphysiological circumstances. All observations, however, were made by the same surgeon. The nature of post-operative morbidity was recorded.

Regurgitation at the mitral valve was graded as follows. Grade I: just detectable by the finger in the left atrium; Grade 2: detectable but not thought to be haemodynamically significant; and Grade 3: haemodynamically significant mitral regurgitation (Belcher, I966).

The notes of patients who had died were studied to discover the cause and date of death.

\section{Results}

Fifty-three patients were found to have heavily calcified mitral valves when explored before valvotomy in a consecutive series of 450 mitral valvotomies performed by the transventricular dilator during the period of January 1958 to December 1966. Further details could not be found in three patients, leaving 50 ( $94 \%$ ) suitable for review. Twentyseven of these patients were seen personally, and adequate follow-up notes and $x$-rays enable the remaining 23 to be included in this study.

The average age of these patients at the time of operation was 44.8 years, and the sex ratio was $\mathrm{I}: \mathrm{I}$. The period of follow-up ranged from 2-Io years, with an average of 7.05 years.

Eleven patients were dead (20\%): two had died in hospital as a result of emboli occurring at or after valvotomy; eight others had died as a result of their chronic heart condition; one other patient died of carcinomatosis just before he was due to attend hospital for assessment (Table I).

The mortality and post-operative results have been grouped together according to

TABLE I Details of patients reviewed after undergoing mitral valvotomy

\begin{tabular}{|c|c|c|}
\hline \multicolumn{3}{|c|}{ Calcified mitral stenosis } \\
\hline $\begin{array}{l}\text { Number of patients } \\
\text { Female } \\
\text { Male } \\
\text { Deaths } \\
\text { Hospital } \\
\text { Late } \\
\text { Unrelated }\end{array}$ & $\begin{array}{r}50 \\
28 \\
22 \\
11 \\
2 \\
8 \\
1\end{array}$ & $\begin{array}{l}(56) \\
(44) \\
(22)\end{array}$ \\
\hline
\end{tabular}

Percentages are given in parentheses.
TABLE $2 A$ comparison of patients who have undergone valvotomy

\begin{tabular}{llllll}
\hline No. & $\begin{array}{l}\text { M:F } \\
\text { ratio }\end{array}$ & $\begin{array}{l}\text { Average } \\
\text { follow-up } \\
(\text { (yr.) }\end{array}$ & $\begin{array}{l}\text { Average } \\
\text { age } \\
(y r .)\end{array}$ & $\begin{array}{l}\text { Atrial } \\
\text { fibrillation } \\
\text { incidence } \\
(\%)\end{array}$ & $\begin{array}{l}\text { Cardiothoracic } \\
\text { ratio } \\
50 \text { per cent } \\
\text { or more } \\
\text { incidence } \\
(\%)\end{array}$ \\
\hline $\begin{array}{l}\text { First } \\
\text { valvotomy } 18\end{array}$ & $1: 1 \cdot 2$ & 7.6 & 45.4 & 60 & 69 \\
$\begin{array}{l}\text { Second } \\
\text { valvotomy } 32\end{array}$ & $1: 1 \cdot 2$ & 6.5 & 44.3 & 64 & 66 \\
\hline
\end{tabular}

whether the patient was undergoing a first or second closed valvotomy. In age, sex ratio, and period of follow-up, these groups are nearly identical. Eighteen patients underwent a first valvotomy and 32 patients a second (Table 2 ).

After a first valvotomy, one patient died two years later of cardiac causes. Ten surviving patients had a 'good' clinical result, five a 'fair' result, and two had a 'poor' result.

After a second valvotomy nine deaths occurred. Two of these occurred in hospital as a result of cerebral emboli occurring just after operation and seven others in the following years of cardiac causes. Six of the survivors had 'good' clinical results, nine 'fair', and eight 'poor' results (Table 3).

These results have been expressed as percentages in the Fig.

In Table 3, the degree of mitral incompetence is related to the clinical result of valvotomy. Five patients $(36 \%)$ having a first valvotomy had no incompetence, and 12 patients $(26 \%)$ having a second had no in-

TABLE 3 Mortality and clinical results as influenced by degree of incompetence before valvotomy

\begin{tabular}{|c|c|c|c|c|c|}
\hline \multirow{2}{*}{$\begin{array}{l}\text { Grade of } \\
\text { incompetence }\end{array}$} & \multirow{2}{*}{$\begin{array}{l}\text { No. of } \\
\text { cases }\end{array}$} & \multicolumn{4}{|c|}{ Clinical result } \\
\hline & & Good & Fair & Poor & Dead \\
\hline & $\begin{array}{l}\text { First } \\
\text { valvotomy }\end{array}$ & & & & \\
\hline 0 & 5 & 3 & 2 & 0 & 0 \\
\hline I & IO & 5 & 3 & I & $\mathbf{I}$ \\
\hline \multirow[t]{2}{*}{2} & 3 & 2 & 0 & $\mathbf{I}$ & 0 \\
\hline & $\begin{array}{l}\text { Second } \\
\text { valvotomy }\end{array}$ & & & & \\
\hline 0 & 12 & 4 & 4 & 2 & 2 \\
\hline $\mathbf{I}$ & Io & I & 4 & 3 & 2 \\
\hline 2 & 9 & $\mathbf{I}$ & $\mathbf{I}$ & 3 & 4 \\
\hline 3 & $\mathbf{I}$ & 0 & 0 & 0 & $\mathbf{I}$ \\
\hline
\end{tabular}


TABLE 4 Comparison of clinical and radiological results after mitral valvotomy

\begin{tabular}{llll}
\hline Clinical results & \multicolumn{2}{l}{ Radiological results } \\
\cline { 2 - 4 } & Good & Fair & Bad \\
\hline First valvotomy & & & \\
Good & 6 & 2 & I \\
Fair & 0 & 4 & 2 \\
Poor & 0 & I & I \\
\hline Second valvotomy & & & \\
Good & 2 & 2 & 3 \\
Fair & 0 & 4 & 4 \\
Poor & 0 & 0 & 8 \\
\hline
\end{tabular}

competence. In both groups the quality of the result decreases as the severity of the incompetence increases, and this was particularly noticeable after a second operation.

The most recent chest $x$-ray of each patient was then graded according to the criteria mentioned in the previous section. These results were compared with the clinical grading of each patient (Table 4). A correlation was found between the quality of clinical and radiological result in patients undergoing a first valvotomy. After a second valvotomy, however, the correlation was less evident, particularly in patients showing a 'good' clinical result.

Four post-operative emboli occurred in

FIG. Comparison of results of first and second valvotomy.

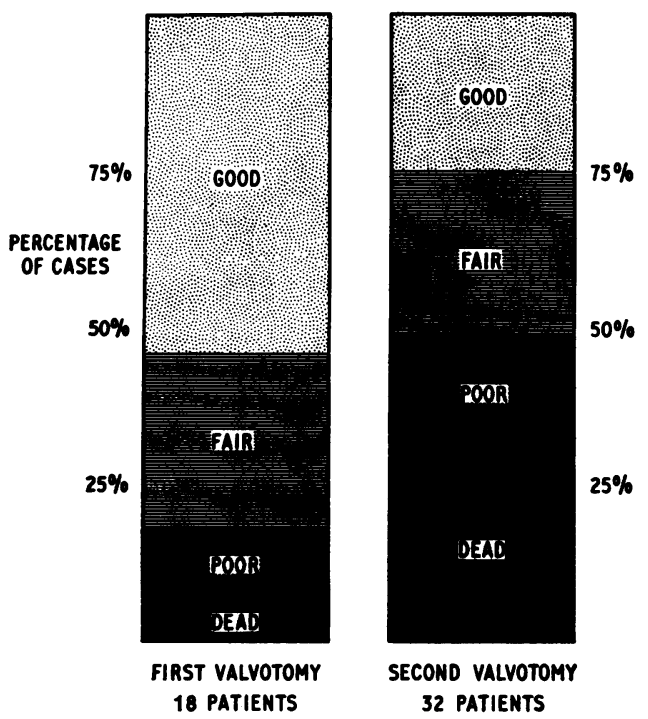

this series of patients $(8 \cdot 0 \%)$. One followed a first valvotomy and the other three followed a second valvotomy. Two of this latter group proved to be fatal.

Four patients have had, or will have, a further operation on the mitral valve. One patient who had a valvotomy for calcific mitral stenosis in 1960, when seen for purpose of assessment for this paper, was suffering from obvious mitral stenosis. Though deteriorating relatively rapidly, she refuses a second operation at the moment.

Three patients who had a second valvotomy have undergone mitral valve replacement. Two of these had 'poor' clinical results. The other, a woman of 50, was graded as 'good' when seen, but after this, deteriorated very rapidly, and mitral valve replacement was advised.

\section{Discussion}

In the years immediately after the introduction of mitral valvotomy, heavy calcification was considered to be a contraindication to valvotomy (Wood, 1954). The reason advanced at that time was the common association of calcification with severe incompetence, and the fear that incompetence would be worsened after valvotomy and the split obtained would be inadequate.

In a series of $\mathbf{4 2}$ mitral valvotomies, Goodwin found an over-all incidence of calcification of 37 per cent and an 8 per cent incidence of heavy calcification (Goodwin et al., 1955). Valvotomies were performed on these heavily calcified valves; there were two deaths and two poor results, five fair results, and eight good results five years after operation.

Michell (1960) found I5 patients with heavy calcification of the valve in a consecutive series of 109 patients undergoing valvotomy. Incompetence was found to have a higher incidence after valvotomy in these patients, but this was not statistically significant.

Belcher (1966) reported the results after valvotomy in 75 patients with heavily calcified valves. There was an 8 per cent hospital mortality and a 32 per cent late death rate; I6 per cent of the survivors had good results and 18 per cent poor results. Restenosis occurred at a rate of 32 per cent. Separate analysis of those cases treated by the transventricular dilator, however, showed that restenosis could be reduced to about 4 per cent and that 42 per cent of patients could expect good results at five years. Mortality was unaffected by the use of this method of mitral valvotomy. The number of cases was only 26, however, and though the initial 
results were encouraging, and compared very favourably with the results of mitral valve replacement at that time, a further study of a larger number of cases was indicated. This paper is a report on this further group of cases and on the subsequent progress of the group initially reported.

In a detailed analysis, Kitchin and Turner (1967) found that transventricular mitral valvotomy on the calcified valve led to a I $7_{7}$ per cent mortality and 47 per cent satisfactory results at five years. Increasing calcification, atrial fibrillation, age above 50 years, cardiothoracic ratio above 50 per cent, and pulmonary hypertension were found to be factors adversely influencing these results.

The trend towards open operations upon the diseased mitral valve has increased, and though only a minority of surgeons advocate the open operation on all cases, the majority would advise open operation on the heavily calcified valve. Analysis of the results we present, however, shows that the results of closed valvotomy are greatly influenced according to whether the valvotomy is a first operation or a second one for restenosis.

In age, sex ratio, duration of follow-up, incidence of incompetence, atrial fibrillation, and cardiothoracic ratio of above 50 per cent, the two groups are similar. There appears to be little difference between the two groups as far as 'fair' and 'poor' results are concerned. The total mortality of a second operation is much higher $(30 \%$ compared with $5.3 \%$ ) and the number of patients with 'good' clinical results fewer (26\% compared with $50 \%$ ).

Furthermore, the grading of the chest $x$-rays of patients with 'good' results from both groups has shown that the proportion of 'good' $x$-rays after a first valvotomy is higher than after a second operation. This suggests that the good results after a second operation will deteriorate sooner than those after a first operation.

To make any far-reaching conclusions on the basis of this small number of cases would be wrong. Nevertheless, the results suggest that second valvotomies on calcified mitral valves are highly dangerous and rarely effective. Since the most recent results of mitral valve replacement show a hospital mortality of 8.9 to 20.2 per cent and a late mortality of $\mathrm{I} \cdot 7$ to II per cent, insertion of a prosthesis is safer and more desirable (Kastor et al., 1968; Edmunds, Wooler, and Watson, 1966; Zerbini et al., 1966; Hamer et al., 1968). Closed valvotomy should be reserved for patients who are having a first operation and who have no adverse factors, such as age, large heart, pulmonary hypertension, and atrial fibrillation. This policy has been adopted by us and will be reviewed when the results of valve replacement improve.

Mitral regurgitation also influences the mortality and quality of post-operative results. We have shown that the greater the incompetence, the worse the results become. Anything more than grade I incompetence, as defined here, is a relative indication for valve replacement.

The rate of restenosis after use of the transventricular dilator is encouragingly low. Only one patient has had restenosis, and a further 4 patients with poor results have undergone valve replacement.

Speculation as to the cause of the difference between first and second valvotomies is inevitable. Increasing derangement of the valve mechanism consequent upon the inexorable progress of calcification may be the answer. Alternatively, all second operations represent a failure of the finger fracture method and the consequent increased duration of valvular defect may exert its toll at the second operation. On the basis of these results, we feel justified in offering closed mitral valvotomy to patients with calcific mitral stenosis, providing that the operation is to be their first and that no more than grade I regurgitation is discovered at operation. Any other valve should be excised and replaced with a prosthesis. Since the degree of calcification and incompetence may often only be fully assessed with the exploring finger, facilities for cardiopulmonary bypass should be available.

Our thanks are due to Dr. M. Honey, Consultant Cardiologist at this hospital, under whose care these patients were initially admitted, and Mr. P. Drury of the Middlesex Hospital for his assistance in preparation of the diagrams.

\section{References}

Belcher, J. R. (1966). What are the indications for mitral valve replacement? British Medical fournal, 2, 1486.

Edmunds, L. H., Wooler, G. H., and Watson, D. A. (1966). Clinical experience with the Alvarez and Starr-Edwards prosthetic mitral valves. Fournal of Thoracic and Cardiovascular Surgery, 51, 185.

Goodwin, J. F., Hunter, J. D., Cleland, W. P., Davies, L. G., and Steiner, R. E. (1955). Mitral valve disease and mitral valvotomy. British Medical fournal, 2, 573.

Hamer, J., Boulton, T., Fleming, J., Hayward, G. W., Hill, I. M., Monro, I., Simon, G., and Tubbs, C. S. (1968). Mitral valve replacement. Longterm results, with particular reference to changes in pulmonary vascular resistance. Thorax, $23, \mathrm{I}$. 
Kastor, J. A., Akbarian, M., Buckley, M. J., Dinsmore, R. E., Sanders, C. A., Scannell, J. G., and Austen, W. G. (1968). Paravalvular leaks and hemolytic anemia following insertion of Starr-Edwards aortic and mitral valves. fournal of Thoracic and Cardiovascular Surgery, 56, 279.

Kitchin, A., and Turner, R. (1967). Calcification of the mitral valve. Results of valvotomy in 100 cases. British Heart fournal, 29, 137.
Michell, G. (1960). Calcific mitral stenosis and mitra valvotomy. British Medical fournal, $1,687$.

Wood, P. (1954). An appreciation of mitral stenosis. Part II. Investigations and results. British Medical fournal, I, III3.

Zerbini, E. J., Bittencourt, D., Pileggi, F., and Jatene, A. (1966). Surgical correction of aortic and mitral valve lesions. Fournal of Thoracic and Cardiovascular Surgery, 51, 474. 